\title{
Infections after CD34-selected or unmanipulated autologous hematopoietic stem cell transplantation
}

Frère P, Pereira M, Fillet G, Beguin Y. Infections after CD34-selected or unmanipulated autologous hematopoietic stem cell transplantation. Eur J Haematol 2006: 76: 102-108. (c) Blackwell Munksgaard 2005.

Abstract: Immune reconstitution may be delayed after CD34-selected compared with unmanipulated autologous peripheral blood stem cell transplantation (PBSCT), resulting in a theoretically increased risk of infections. In a case-control matched study we compared the incidence of infection in 25 recipients of CD34-selected PBSC (CD34 group) and 75 recipients of unmanipulated PBSC (PBSC group) transplants. The population included 52 males and 48 females suffering from nonHodgkin's lymphoma $(n=32)$, Hodgkin's disease $(n=8)$, multiple myeloma $(n=40)$ or breast cancer $(n=20)$. Neutrophil engraftment was comparable in the two groups. The actuarial incidence of infection was similar in the two groups ( $56 \%$ vs. $49 \%$ at day 30 , and $70 \%$ vs. $64 \%$ at $1 \mathrm{yr}$ respectively). The proportion of patients with 1,2 or 3 infections, the number of infectious event per patient (1.32 vs. 1.04; NS), the number of infections before day 15 or 30 , between days 31 and 100 or after day 100, the risk of varicella-zoster virus or cytomegalovirus infection or disease, or the use of antibiotic or antifungal therapy, were not increased in the CD34 compared with the PBSC group. The main agents responsible for infection were bacteria, particularly gram-positive cocci, in both groups. Bacteremia accounted for $33 \%$ of all infectious events in the CD34 group vs. $16 \%$ in the PBSC group $(P<0.05)$. Fungal infections were rare. In conclusion, our results do not support the notion that CD34-selection of the graft is associated with an increased rate of infection after autologous PBSC transplantation. The role of extended infection prophylaxis should be evaluated.

\section{Pascale Frère, Maguy Pereira, Georges Fillet, Yves Beguin}

Division of Hematology, Department of Medicine, University of Liège, Liège, Belgium

Key words: hematopoietic stem cell transplantation; autologous transplantation; CD34 selection; infections

Correspondence: Yves Beguin MD, Department of Hematology, University of Liège, CHU Sart-Tilman, 4000 Liège, Belgium

Tel: +32- 4-3667201

Fax: $+32-4-3668855$

e-mail yves.beguin@chu.ulg.ac.be

Accepted for publication 10 August 2005
High-dose chemotherapy followed by autologous stem cell transplantation can improve survival for several categories of cancer patients (1-3). Peripheral blood stem cells (PBSC) have replaced bone marrow (BM) in this indication because they allow a more rapid trilineage hematopoietic recovery, leading to a reduction in the incidence of febrile neutropenia, duration of hospital stay and utilization of blood products (4). Despite this, relapse and tumor contamination of the graft has been advocated as a major cause of failure of PBSC transplant. As the CD34 antigen is a surface marker expressed in early hematopoietic progenitors but is not present in mature hematopoietic cells or most tumor cells, CD34 selection has been used to reduce the amount of contaminant tumor cells in the stem cell product $(5,6)$. Although the number of contaminating tumor cells can be reduced by two to four logs, it is not yet known whether CD34 selection would significantly impact on the incidence of relapse $(5,7)$. However, there are suggestions that immune reconstitution may be delayed with CD34 selection because of the removal of $\mathrm{T}$ cells, natural killer cells and monocytes (8-11). The result could be an increased incidence of infectious complications. Some small series of patients have reported a higher incidence of infections (12-14), in particular of viral infections (15-17), but others have not (8). We therefore compared in a retrospective case-control matched study the incidence of infection in 25 CD34-selected PBSC transplant recipients and in 75 patients receiving unmanipulated PBSC in our institution. 


\section{Patients and methods}

Patients

Patients' characteristics are displayed in Table 1. The study population included all patients receiving a CD34-selected PBSC autograft in our center (CD34 group, $n=25$ ), as part of pilot studies. We then proceeded to select 75 controls in our database of 327 patients receiving an unmanipulated PBSC

Table 1. Patients' characteristics

\begin{tabular}{|c|c|c|c|}
\hline & CD34 group & PBSC group & $P$-value \\
\hline Age (yr) & $51 \pm 11$ & $52 \pm 11$ & NS \\
\hline \multicolumn{4}{|l|}{ Sex } \\
\hline Female & $11(44)$ & 37 (49) & \multirow[t]{2}{*}{ NS } \\
\hline Male & $14(56)$ & $38(51)$ & \\
\hline \multicolumn{4}{|l|}{ Diagnosis } \\
\hline Non-Hodgkin's lymphoma & $8(32)$ & $24(32)$ & \multirow[t]{4}{*}{ NS } \\
\hline Hodgkin's disease & $2(8)$ & $6(8)$ & \\
\hline Multiple myeloma & $10(40)$ & $30(40)$ & \\
\hline Breast cancer & $5(20)$ & $15(20)$ & \\
\hline Lines of treatment & $2.6 \pm 1.1$ & $2.4 \pm 1.1$ & NS \\
\hline \multicolumn{4}{|l|}{ Status at transplant } \\
\hline CR 1 and 2 & $6(24)$ & $18(24)$ & \multirow[t]{3}{*}{ NS } \\
\hline Other first line & $5(20)$ & $25(33)$ & \\
\hline Relapse & $14(56)$ & $32(43)$ & \\
\hline \multicolumn{4}{|l|}{ Conditioning regimen } \\
\hline TBI & $13(52)$ & $20(27)$ & \multirow[t]{8}{*}{0.020} \\
\hline $12 \mathrm{GY}+\mathrm{CY} 120$ & $4(16)$ & $11(15)$ & \\
\hline $12 \mathrm{GY}+\mathrm{Mel} 140$ & $9(36)$ & $9(12)$ & \\
\hline Chemotherapy & $12(48)$ & $55(73)$ & \\
\hline Mel 200 & 1 (4) & $19(25)$ & \\
\hline BEAM & $6(24)$ & $16(21)$ & \\
\hline CTCb & $5(20)$ & $15(20)$ & \\
\hline Other & $0(0)$ & $5(7)$ & \\
\hline \multicolumn{4}{|l|}{ Transplant number } \\
\hline First & $15(60)$ & $48(64)$ & \multirow[t]{2}{*}{ NS } \\
\hline Second & $10(40)$ & $27(36)$ & \\
\hline \multicolumn{4}{|l|}{ Cytomegalovirus status } \\
\hline Positive & $15(60)$ & 44 (59) & \multirow[t]{2}{*}{ NS } \\
\hline Negative & $10(40)$ & $31(41)$ & \\
\hline \multicolumn{4}{|l|}{ Herpes simplex virus status } \\
\hline Positive & $24(96)$ & $62(83)$ & \multirow[t]{2}{*}{ NS } \\
\hline Negative & 1 (4) & $12(17)$ & \\
\hline \multicolumn{4}{|l|}{ Varicella-zoster virus status } \\
\hline Positive & $24(96)$ & $61(81)$ & \multirow[t]{2}{*}{ NS } \\
\hline Negative & 1 (4) & $9(19)$ & \\
\hline \multicolumn{4}{|l|}{ Mucositis } \\
\hline Grade 0 & $13(52)$ & $26(35)$ & \multirow[t]{3}{*}{ NS } \\
\hline Grade 1 & $8(32)$ & $31(41)$ & \\
\hline Grade 2 & $4(16)$ & $18(24)$ & \\
\hline \multicolumn{4}{|l|}{ Gastrointestinal toxicity } \\
\hline Grade 0 & $12(48)$ & 37 (49) & \multirow[t]{3}{*}{ NS } \\
\hline Grade 1 & $13(52)$ & 37 (49) & \\
\hline Grade 2 & $0(0)$ & $1(2)$ & \\
\hline CD34+ cells infused & $10.2 \pm 11.3$ & $13.2 \pm 13.3$ & NS \\
\hline Median days of G-CSF & 12 & 10 & NS \\
\hline Median days to $500 \mathrm{PMN}$ & 10 & 9 & NS \\
\hline Monocytes on day 30 & $593 \pm 76$ & $670 \pm 52$ & NS \\
\hline Lymphocytes on day 30 & $866 \pm 159$ & $1061 \pm 88$ & NS \\
\hline
\end{tabular}

Percentage values are given in parentheses. CR, complete remission; Gy, Grays; Cy, cyclophosphamide; Mel, melphalan; BEAM, BCNU + VP16 + ARA-C + melphalan; CTC6, cyclophosphamide + thiotepa + carboplatin. transplant during the same period of time. After exclusion of patients receiving PBSC + BM $(n=$ 30 ), patients with a diagnosis other than multiple myeloma (MM), non-Hodgkin's lymphoma (NHL), Hodgkin's disease (HD) or breast cancer (BC) $(n=58)$ and patients with a follow-up $<30 \mathrm{~d}$ $(n=12), 223$ patients were available for matching. The CD34 group was then matched $1: 3$ with the unmanipulated patients (PBSC group) on the basis of diagnosis, disease status at time of transplant and transplantation number (first or second transplant). This was achieved for NHL, HD and BC but not for MM because CD34 selection in this indication was only performed for second transplantation after relapse. Therefore, a higher proportion of MM patients in the CD34 group were in relapse and fewer in first partial remission. The median follow-up was $771 \mathrm{~d}$. All patients gave written informed consent to the collection and analysis of their clinical data and this was approved by the Ethics Committee of the University of Liège.

\section{PBSC collection and CD34 selection}

Peripheral blood stem cell were mobilized in all patients by a combination of disease-oriented chemotherapy and granulocyte colony-stimulating factor (G-CSF) $5 \mu \mathrm{g} / \mathrm{kg} / \mathrm{d}$. PBSC were harvested by leukapheresis as previously described $(6,18)$. CD34 selection was carried out with an avidin immunoaffinity column device (Ceprate ${ }^{\circledR}$ SC system; CellPro, Bothell, WA, USA) as previously described (6). Unmanipulated as well as CD34-selected cells were frozen in $7.5 \%$ DMSO to be thawed and infused through a central catheter, as previously described (6).

\section{Clinical management}

Until engraftment, patients were kept in laminar air flow rooms and received chlorhexidine mouthwashes, aerosolized amphotericin $\mathrm{B}$, oral ciprofloxacin (500 $\mathrm{mg}$ b.i.d.) as well as G-CSF $(5 \mu \mathrm{g} / \mathrm{kg} / \mathrm{d})$. Patients also received acyclovir $\left(250 \mathrm{mg} / \mathrm{m}^{2}\right.$ b.i.d. intravenously and then orally as soon as feasible until day 100), oral antifungal prophylaxis with either $400 \mathrm{mg}$ itraconazole $(n=75)$ or $400 \mathrm{mg}$ fluconazole if itraconazole was not tolerated $(n=$ 25) until day 100 and aerosolized pentamidine until day 120. All patients were managed with a totally implanted Porth-A-Cath ${ }^{\circledR}$ catheter (Bard, Covington, GA, USA) that remained in place at least until 1 yr post-transplant.

In case of fever, above $38.3^{\circ} \mathrm{C}$ once or above $38^{\circ} \mathrm{C}$ on three consecutive measurements, empirical antibiotic therapy was started with a combination of ceftazidime + vancomycin (until 2000) or 
cefepime + amikacin (after 2000) (19). Patients were weekly screened for cytomegalovirus (CMV) by culture and antigenemia in blood and urine before 1996 and by PCR in blood since 1996. Hence $55 \%$ in the PBSC group vs. $25 \%$ in the CD34 group were screened by PCR. Preemptive therapy with ganciclovir $(10 \mathrm{mg} / \mathrm{kg}$ i.v. thrice weekly) was initiated after a positive antigenemia or culture (before 1996) or a positive PCR (since 1996) and discontinued after two consecutive negative results. Other viruses, in particular respiratory viruses, are not routinely screened in our institution.

\section{Definitions}

Bacteria were classified into five categories taking into account both their relative frequency and their biological characteristics. These categories were: (i) streptococci (including pneumococci and enterococci), (ii) coagulase-negative staphylococci, (iii) other gram-positive bacteria (including Staphylococcus aureus), (iv) anerobic bacteria (bacteria requiring absence of oxygen for growth, including both strict anaerobes and aerotolerant bacteria), (v) gram-negative bacteria (including pseudomonas) (19). We used the definitions of the Infectious Diseases Working Party of the EBMT for diagnostic of bacteremia, fungemia, herpes simplex virus (HSV) or varicella-zoster virus (VZV) infections, CMV infection or disease (20). As quantitative assessment of bacteria load was not available, bacteremia could not be separated between those linked and those not linked to the catheter. Invasive fungal infections were defined according to the EORTC criteria (21). Fever of unknown origin (FUO) was defined as fever alone without any clinical sign or bacteriological documentation. Toxicities were graded using the Bearman toxicity scale that was specifically developed for the setting of stem cell transplantation (22).

\section{Statistical analysis}

Patients were censored at the time of disease progression to avoid the confounding effect of disease and chemotherapy-induced neutropenia. Chi-square tests, unpaired $t$-tests or one-way ANOvA were used to compare differences between groups, as appropriate. The number of events in the two groups was compared by the $Z$-test. Times to hematopoietic recovery or infectious events were studied by life table analyses and Wilcoxon rank tests were used for comparison between groups. Statistical analyses were done using Microsoft Excel (Microsoft Corp., Redmond, WA, USA) and GraphPad Prism (GraphPad Software, San Diego, CA, USA) software.

\section{Results}

The median number of CD34 cells infused (purity $67 \pm 19 \%$ ), the median duration of G-CSF therapy and neutrophil and monocyte engraftment were similar in the two groups (Table 1). Platelet and red blood cell engraftment and transfusion independence were also quite comparable (data not shown). Lymphocyte counts were lower in the CD34 group on day $14(138 \pm 150$ vs. $535 \pm 607$, $P=0.0027)$ but quite similar thereafter throughout to day 365. CD3, CD4 and CD8 cell counts were available in a minority of patients. Whereas they were all lower through to day $42(P<0.05)$, the differences were no longer present at later time points. CD56 counts were similar throughout the post-transplant course. Serum IgG were higher in the CD34 group on day $100(17.19 \pm 4.47 \mathrm{~g} / \mathrm{L}$ vs. $12.28 \pm 3.56 \mathrm{~g} / \mathrm{L}, P=0.0002)$ but similar on days 180 and 365. Serum IgM were lower in the CD34 group on day $180 \quad(0.35 \pm 0.14 \mathrm{~g} / \mathrm{L} \quad$ vs. $0.63 \pm 0.64 \mathrm{~g} / \mathrm{L}, P=0.0107)$, but there were no other differences for IgM and IgA. Mucosal or gastrointestinal toxicities were similar. Only two patients in the PBSC group had hemorrhagic cystitis (negative viral cultures). Progression-free survival was not significantly different in the CD34 group compared with the PBSC group and similar numbers of patients were censored for disease progression at day 100 and at $1 \mathrm{yr}$. The main cause of death was the initial disease in both groups (100\% of the deaths in the CD34 group and $86 \%$ in the PBSC group). Infection was the main cause or a contributing cause of death in, respectively, $0 \%$ and $20 \%$ of patients in the CD34 group compared with $1 \%(\mathrm{NS})$ and $10 \%(\mathrm{NS})$, respectively, in the PBSC group.

The proportion of patients with at least one $(68 \%$ vs. $68 \%)$, two $(24 \%$ vs. $17 \%)$ or three $(4 \%$ vs. $4 \%$ ) infections after transplantation was not different in the CD34 and PBSC groups and this holds true for infections occurring before day 100 . The actuarial incidence of infection at day 30, day 100 and $1 \mathrm{yr}$ was similar in the CD34 and PBSC groups (Fig. 1A). As each patient could develop more than one infectious episode, we also calculated the number of events in each group at different time intervals after transplantation (Table 2). There was no difference between the two groups (1.32 event/patient vs. 1.04 event/patient), even when FUO were excluded (1.04 event/patient vs. 0.81 event/patient). Indeed, $45 \%(15 / 33)$ and $53 \%$ $(41 / 78)$ of all infections occurred during the first $15 \mathrm{~d}$ (i.e. during neutropenia) in the CD34 and PBSC groups respectively. Bacteria were involved in most cases (21 vs. 56), while similarly low numbers of fungal (3 vs. 6), viral (7 vs. 13) and 

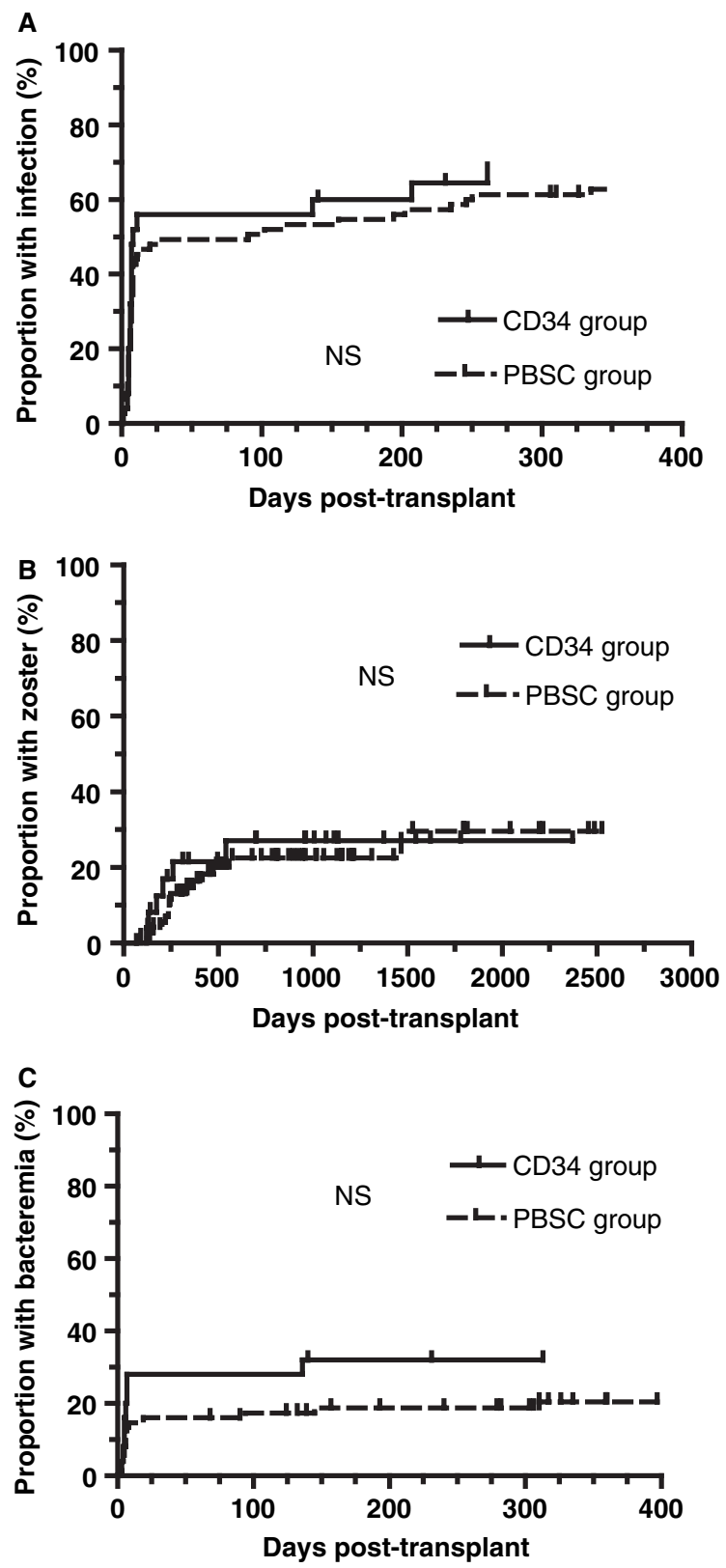

Fig. 1. Actuarial incidence of any infection (A), zoster infection (B) and bacteremia (C) in the CD34 group compared with the PBSC group. parasitic (0 vs. 0$)$ infections were observed in the CD34 and PBSC groups respectively. During initial hospitalization, there was no difference in the median number of days with fever ( $1 \mathrm{~d}$ vs. $1 \mathrm{~d})$, with amphotericin $\mathrm{B}(0 \mathrm{~d}$ vs. $0 \mathrm{~d})$ or with antibiotics ( $8 \mathrm{~d}$ vs. $5 \mathrm{~d}$ ) in the CD34 group compared with the PBSC group.

Overall the CD34 and PBSC groups had similar risks of viral infections despite greater usage of TBI in the CD34 group (Table 2). Five vs. eight cases of dermatomal and one vs. three cases of disseminated VZV infection occurred in the CD34 and PBSC groups respectively. The actuarial proportion of patients with VZV infection at $1 \mathrm{yr}$ or $5 \mathrm{yr}$ was similar in the two groups (Fig. 1B). CMV reactivation occurred in $2 / 25(8 \%)$ in the CD34 group vs. $5 / 75(6 \%)$ in the PBSC group, but CMV disease was only observed in the PBSC group (one case of gastroenteritis before day 30 and one case of myelosuppression before day 100). CMV infection or disease were never encountered after day 100 .

Bacteremia occurred in $8 / 25$ patients $(32 \%)$ in the CD34 group and in $15 / 75$ patients $(20 \%)$ in the PBSC group $(P=0.2169)$, representing a total of 11 vs. 15 episodes $(P<0.10)$. The actuarial risk of bacteremia at day 30 or $1 \mathrm{yr}$ was similar in the CD34 and PBSC groups respectively (Fig. 1C) $(P=0.2042)$. The vast majority of bacteremia took place during neutropenia in both groups, with only six events occurring after day 15. Bacteremia accounted for $33 \%$ of all infectious events in the CD34 group vs. $16 \%$ in the PBSC group $(P<0.05)$. Among bacteremia, 38\% were due to coagulase-negative staphylococci, $19 \%$ to streptococci and $19 \%$ to gram-negative bacteria, with similar proportions in the two groups. There was only one candidemia in the CD34 group.

The number of infectious events other than bacteremia or viral infections was quite comparable in the two groups ( 0.64 episode/patient vs. 0.64 episode/patient). Pneumonias accounted for about $25 \%$ of these infections, mostly of bacterial origin and very few of fungal origin (one vs. two, respectively). The gastrointestinal tract was the

Table 2. Number of infectious complications ( $n$ per patient) in the two groups according to time after transplantation. Infections are classified by etiologic agent

\begin{tabular}{|c|c|c|c|c|c|c|c|c|c|c|c|c|}
\hline & \multicolumn{3}{|c|}{ Days $0-30$} & \multicolumn{3}{|c|}{ Days 31-100 } & \multicolumn{3}{|c|}{ Days $>100$} & \multicolumn{3}{|c|}{ Total } \\
\hline & $\mathrm{CD} 34$ group & PBSC group & $P$-value & CD34 group & PBSC group & $P$-value & CD34 group & PBSC group & $P$-value & CD34 group & PBSC group & $P$-value \\
\hline All infections & $21(0.84)$ & $48(0.64)$ & NS & $0(0.00)$ & $7(0.09)$ & $<0.01$ & $12(0.48)$ & $23(0.31)$ & NS & $33(1.32)$ & $78(1.04)$ & NS \\
\hline Viral & $1(0.04)$ & $1(0.01)$ & NS & $0(0.00)$ & $1(0.01)$ & NS & $6(0.24)$ & $11(0.15)$ & NS & $7(0.28)$ & $13(0.17)$ & NS \\
\hline Fungal & $3(0.12)$ & $5(0.07)$ & NS & $0(0.00)$ & $0(0.00)$ & NS & $0(0.00)$ & $1(0.01)$ & NS & $3(0.12)$ & $6(0.08)$ & NS \\
\hline Bacterial & $17(0.68)$ & $40(0.53)$ & NS & $0(0.00)$ & $6(0.08)$ & $<0.05$ & $4(0.16)$ & $10(0.13)$ & NS & $21(0.84)$ & $56(0.75)$ & NS \\
\hline Parasitic & $0(0.00)$ & $0(0.00)$ & NS & $0(0.00)$ & $0(0.00)$ & NS & $0(0.00)$ & $0(0.00)$ & NS & $0(0.00)$ & $0(0.00)$ & NS \\
\hline Unknown & $0(0.00)$ & $2(0.03)$ & NS & $0(0.00)$ & $0(0.00)$ & NS & $2(0.08)$ & $1(0.01)$ & NS & $2(0.08)$ & $3(0.04)$ & NS \\
\hline
\end{tabular}

$P$-values are given for the calculated incidence per patient. Infections occurring after disease progression are excluded. 
most common site of infection in the PBSC group (11 cases) but was not encountered in the CD34 group $(P<0.001)$.

\section{Discussion}

We conducted a retrospective matched case-control study of infections in patients treated by high-dose chemotherapy and autologous PBSC transplantation with or without CD34 cell selection. The CD34 group was matched $1: 3$ with the PBSC group on the basis of diagnosis, disease status and transplantation number. This was not achieved for $\mathrm{MM}$ because CD34 selection in this indication was only carried out for second transplantation after relapse. Hence, patients in the CD34 group had somewhat more advanced disease and received more often TBI, but otherwise the two groups were very well balanced (Table 1). This greater use of TBI could theoretically increase the risk of infection.

Overall, we did not find any difference in the proportion of patients with any infection between recipients of CD34-selected or unmanipulated PBSC grafts. Contrary to some other studies (1214), but in agreement with Peggs et al. (8), we did not find an increased incidence of bacterial infections in recipients of CD34-selected autografts. This could theoretically be due to an increase of infections in our PBSC group. However, this did not appear to be the case in comparison with previous studies in the literature $(3,6,23-27)$. The mechanisms of this increased rate of bacterial infection in other studies with CD34 selection may relate to difference in neutrophil engraftment (14) (not encountered in our study), whereas others did not report neutrophil recovery $(12,13)$. In addition, there have been suggestions that TBI (28) or a diagnosis of myeloma rather than BC (29) were significant risk factors after CD34-selected PBSC transplantation. However, we did not observe such a trend for higher rates of infections in patients receiving TBI and the respective numbers of myeloma or BC patients were perfectly matched. There was no delay in neutrophil engraftment in our CD34 group. Whereas delayed hematopoietic recovery has sometimes been described in the literature $(5,14,30)$, it has not been observed in randomized studies (7) and we have shown previously that neutrophil counts remained quite similar in CD34-selected and unselected patients over periods of months post-transplant (6). Finally, our policy of extended quinolone prophylaxis may have played a protective role. Indeed some other studies either administered prophylactic antibiotics only when the neutrophil count was $<0.5 \times 10^{9} / \mathrm{L}$ $(12,15)$ and fluconazole for $1 \mathrm{yr}(31)$, but most did not use any prophylaxis for bacterial $(8,11,13)$ or fungal infections $(8,11-13,15)$. Fungal infections were rather uncommon, in agreement with the short duration of neutropenia considered as the most important host defense mechanism against fungal infections in this setting, and there was no parasitic infection.

Bacteremia accounted for a higher proportion of all infections in the CD34 compared with the PBSC group. The vast majority of bacteremia occurred during neutropenia that was of comparable length in the two groups. In agreement with the literature (32-34), most episodes of bacteremia were caused by gram-positive coagulase-negative staphylococci and streptococci. This could be due to the systematic use of central venous catheters, but the type and duration of central intravascular device were identical in the two populations. This could also relate to mucositis and gastrointestinal toxicity, but their incidence was similar in the two groups.

As CD34 selection may be associated with qualitative or quantitative differences in immune reconstitution as after allogeneic T-cell depletion $(5,8-11)$, one could expect a surge in viral, and in particular CMV, infections. However, the rate of CMV infection was very low in both groups, and there were only two cases of CMV disease, both in the PBSC group. The actuarial rate of VZV infection was quite similar in the two groups, with very few cases of early zoster/varicella but with VZV as the major agent responsible for infections after day 100. Thus, overall, in our experience, CD34 selection was not associated with an increased risk of viral infection. This may come as a surprise as several studies have shown an increased incidence of viral, and in particular of CMV, infections in recipients of CD34-selected grafts (12, 15-17). In addition, the risk of Epstein-Barr virus lymphoproliferative disease appears to be enhanced $(31,35)$. However, other studies also did not describe any augmentation of CMV and other viral infections $(8,13)$. These differences among studies can be partly due to different patient selection criteria or different prophylaxis policies. In particular, some studies were carried out without any acyclovir prophylaxis $(11,13)$, but some used acyclovir $(8,12,15)$ up to 1 yr post-transplant $(31)$. Our policy of prolonged acyclovir prophylaxis may have protected many patients from VZV infection until more complete immune recovery. Differences could also relate to low infection detection rates when viral cultures and CMV PCR are not routinely performed, as in our early patients. Indeed, our result may be an underestimate because of the lack of stringent monitoring for viral infections. The speed of immune reconstitution may also correlate inversely with the purity of the CD34-selected product, hence with the degree of 
T-cell depletion, which was less severe in our series. At least early monocyte and overall lymphocyte recoveries were similar in our two groups. However, the retrospective nature of our analysis does not allow us to evaluate immune recovery more thoroughly, in particular for CD4 counts.

In conclusion, our results do not support the notion that CD34-selection of the graft is associated with an increased rate of infection after autologous PBSC transplantation. However, the absence of a significant difference between cases and controls may relate to the relatively low numbers of patients (although our study is one of the largest, with 100 carefully matched patients) and the relative heterogeneity of our population. Alternatively, this could also be due to a more vigorous infection prophylaxis in our patients compared with those reported in other studies.

\section{References}

1. Philip T, Guglielmi C, Hagenbeek A, et al. Autologous bone marrow transplantation as compared with salvage chemotherapy in relapses of chemotherapy-sensitive nonHodgkin's lymphoma. N Engl J Med 1995;333:1540-1545.

2. Schmitz N, Pfistner B, Sextro M, et al. Aggressive conventional chemotherapy compared with high-dose chemotherapy with autologous haemopoietic stem-cell transplantation for relapsed chemosensitive Hodgkin's disease: a randomised trial. Lancet 2002;359:2065-2071.

3. Attal M, Harousseau JL, Stoppa AM, et al. A prospective, randomized trial of autologous bone marrow transplantation and chemotherapy in multiple myeloma. Intergroupe Francais du Myelome. $\mathrm{N}$ Engl J Med 1996;335:91-97.

4. Schmitz N, Linch DC, Dreger P, et al. Randomised trial of filgrastim-mobilised peripheral blood progenitor cell transplantation vs. autologous bone-marrow transplantation in lymphoma patients. Lancet 1996;347:353-357.

5. Watanabe $\mathrm{T}$, Kawano $\mathrm{Y}$, Watanabe A, Takaue $\mathrm{Y}$. Autologous and allogeneic transplantation with peripheral blood CD34 + cells: a pediatric experience. Haematologica 1999;84:167-176.

6. Beguin Y, Baudoux E, Sautois B, et al. Hematopoietic recovery in cancer patients after transplantation of autologous peripheral blood CD34+ cells or unmanipulated peripheral blood stem and progenitor cells. Transfusion 1998;38:199-208.

7. Stewart AK, Vescio R, Schiller G, et al. Purging of autologous peripheral-blood stem cells using CD34 selection does not improve overall or progression-free survival after high-dose chemotherapy for multiple myeloma: results of a multicenter randomized controlled trial. J Clin Oncol 2001;19:3771-3779.

8. Peggs KS, Verfuerth S, Pizzey A, et al. Reconstitution of T-cell repertoire after autologous stem cell transplantation: influence of CD34 selection and cytomegalovirus infection. Biol Blood Marrow Transplant 2003;9:198-205.

9. Rutella S, Pierelli L, Sica S, Rumi C, Leone G. Transplantation of autologous peripheral blood progenitor cells: impact of CD34-cell selection on immunological reconstitution. Leuk Lymphoma 2001;42:1207-1220.

10. Nachbaur D, Kropshofer G, Heitger A, et al. Phenotypic and functional lymphocyte recovery after CD34+enriched vs. non-T cell-depleted autologous peripheral blood stem cell transplantation. J Hematother Stem Cell Res 2000;9:727-736.

11. Malphettes M, Carcelain G, Saint-Mezard P, et al. Evidence for naive $\mathrm{T}$-cell repopulation despite thymus irradiation after autologous transplantation in adults with multiple myeloma: role of ex vivo $\mathrm{CD} 34+$ selection and age. Blood 2003;101:1891-1897.

12. Crippa F, Holmberg L, Carter RA, et al. Infectious complications after autologous CD34-selected peripheral blood stem cell transplantation. Biol Blood Marrow Transplant 2002;8:281-289.

13. Friedman J, Lazarus HM, Koc ON. Autologous CD34+ enriched peripheral blood progenitor cell (PBPC) transplantation is associated with higher morbidity in patients with lymphoma when compared to unmanipulated PBPC transplantation. Bone Marrow Transplant 2000;26:831836.

14. Goerner M, Wandt H, Schafer-Eckart K, Birkmann J, Denzel T, Gallmeier WM. The use of CD34+-selected PBPC after high-dose chemotherapy in breast cancer patients is associated with prolonged recovery time and increased infectious complications. J Hematother Stem Cell Res 1999;8:387-391.

15. Holmberg LA, Boeckh M, Hooper $\mathrm{H}$, et al. Increased incidence of cytomegalovirus disease after autologous CD34-selected peripheral blood stem cell transplantation. Blood 1999;94:4029-4035.

16. Sica S, Sora F, Chiusolo P, et al. Early viral complications after autologous CD34-selected peripheral blood stem cell transplantation. Bone Marrow Transplant 2000;26:587588.

17. Takeshima $M$, Takamatsu $\mathrm{H}$, Iida $\mathrm{M}$, Mochizuki $\mathrm{Y}$, OKumura H, Yoshida T. Frequent viral infections and delayed CD4 + cell recovery following CD34 + cell-selected autologous peripheral blood stem cell transplantation. Int J Hematol 1999;70:193-199.

18. Sautois B, Fraipont V, Baudoux E, et al. Peripheral blood progenitor cell collections in cancer patients: analysis of factors affecting the yields. Haematologica 1999;84:342349.

19. Frere P, Hermanne JP, Debouge MH, De Mol P, Fillet G, BEGUIN Y. Bacteremia after hematopoietic stem cell transplantation: incidence and predictive value of surveillance cultures. Bone Marrow Transplant 2004;33:745-749.

20. Cordonnier C. Definitions of infectious diseases and complications after stem cell transplant. 2005. Available online at http://www.ebmt.org/5WorkingParties/IDWP/ wparties-id6.htm.

21. Ascioglu S, Rex JH, De Pauw B, et al. Defining opportunistic invasive fungal infections in immunocompromised patients with cancer and hematopoietic stem cell transplants: an international consensus. Clin Infect Dis 2002:34:7-14

22. Bearman Si, Appelbaum FR, Buckner CD, et al. Regimen-related toxicity in patients undergoing bone marrow transplantation. J Clin Oncol 1988;6:1562-1568.

23. Blume KG, Thomas ED. A review of autologous hematopoietic cell transplantation. Biol Blood Marrow Transplant 2000;6:1-12.

24. JASSAK PF, Riley MB. Autologous stem cell transplant: an overview. Cancer Pract 1994;2:141-145.

25. Kolbe K, Domkin D, Derigs HG, Bhakdi S, Huber C, AULITZKY WE. Infectious complications during neutropenia subsequent to peripheral blood stem cell transplantation. Bone Marrow Transplant 1997;19:143-147.

26. Goldman JM, Schmitz N, Niethammer D, Gratwohl A. Allogeneic and autologous transplantation for haematological diseases, solid tumours and immune disorders: current practice in Europe in 1998. Accreditation Sub-Committee of the European Group for Blood and 


\section{Frère et al.}

Marrow Transplantation. Bone Marrow Transplant 1998;21:1-7.

27. Barton T, Collis T, Stadtmauer E, Schuster M. Infectious complications the year after autologous bone marrow transplantation or peripheral stem cell transplantation for treatment of breast cancer. Clin Infect Dis 2001;32:391-395.

28. Maeda S, Kagami Y, Ogura M, et al. CD34+-selected autologous peripheral blood stem cell transplantation conditioned with total body irradiation for malignant lymphoma: increased risk of infectious complications. Int $\mathbf{J}$ Hematol 2001;74:214-221.

29. De Rosa L, Anghel G, Pandolfi A, Riccardi M, AmoDEO R, MAJOLINo I. Hemopoietic recovery and infectious complications in breast cancer and multiple myeloma after autologous CD34 + cell-selected peripheral blood progenitor cell transplantation. Int J Hematol 2004;79:85-91.

30. Gandhi M, Jestice H, Scott M, et al. A comparison of CD34 + cell selected and unselected autologous peripheral blood stem cell transplantation for multiple myeloma: a case controlled analysis. Bone Marrow Transplant 1999;24:369-375.

31. Nash RA, Dansey R, Storek J, et al. Epstein-Barr virusassociated posttransplantation lymphoproliferative dis- order after high-dose immunosuppressive therapy and autologous CD34-selected hematopoietic stem cell transplantation for severe autoimmune diseases. Biol Blood Marrow Transplant 2003;9:583-591.

32. Reich G, Mapara MY, Reichardt P, Dorken B, MASChMEYER G. Infectious complications after high-dose chemotherapy and autologous stem cell transplantation: comparison between patients with lymphoma or multiple myeloma and patients with solid tumors. Bone Marrow Transplant 2001;27:525-529.

33. Salazar R, Sola C, Maroto P, et al. Infectious complications in 126 patients treated with high-dose chemotherapy and autologous peripheral blood stem cell transplantation. Bone Marrow Transplant 1999;23:27-33.

34. ToOr AA, VAN BURIK JA, WeISDORF DJ. Infections during mobilizing chemotherapy and following autologous stem cell transplantation. Bone Marrow Transplant 2001;28:1129-1134.

35. Powell Jl, Bunin NJ, Callahan C, Aplenc R, Griffin G, GRUPP SA. An unexpectedly high incidence of Epstein-Barr virus lymphoproliferative disease after CD34+ selected autologous peripheral blood stem cell transplant in neuroblastoma. Bone Marrow Transplant 2004;33:651-657. 